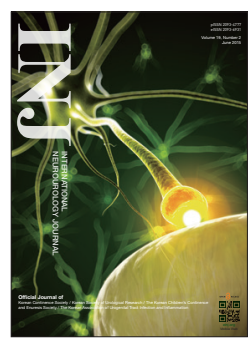

\title{
Application of Oncology Research to Resolve a Problem in Neurourology
}

\author{
Tack Lee (ib http://orcid.org/0000-0001-8508-9099 \\ Editor-in-Chief \\ Department of Urology, Inha University School of Medicine, Incheon, Korea \\ E-mail: lee.tack33@gmail.com
}

The urinary bladder is a spherical organ composed of smooth muscle with a unique contractile property. On voiding cystourethrograms usually observed in our clinic, $300-400 \mathrm{~mL}$ of fluid in the full bladder completely disappears after voiding. This is possible due to shortening of the outer circumference of the bladder by more than $70 \%$. If the smooth muscle of the bladder wall were to be replaced by skeletal muscle under the same influence of central and peripheral nervous systems, only about 30\% length change would be possible, resulting in significant residual urine [1]. This suggests that cellular signaling and regulatory networks in the detrusor muscle greatly influence the change in bladder contractility in several clinically important conditions such as overactive bladder or benign prostatic hyperplasia. However, information on this topic is unclear, and another target having a central role in contractility control will need to be added.

A live cell is similar to a rechargeable battery [2]. Energy released from adenosine triphosphate (ATP) or adenosine diphosphate hydrolysis is used to supply energy for cellular processes. The discharging cellular batteries are continuously recharged by catabolism through dynamic feedback mechanisms that monitor intracellular energy levels. Adenosine monophosphate (AMP)-activated protein kinase (AMPK) fulfills this role, and this activity is regulated allosterically by the ratio of AMP and ATP [2,3]. Although it is best known for its role as a key sensor of cellular energy in almost all eukaryotes, AMPK, as shown recently, regulates almost all cellular functions, including cell growth and proliferation, and mitochondrial homeostasis
$[2,4]$, and has some interconnections to signaling pathways involved in cancer biology and contractility changes $[5,6]$. Furthermore, recent discoveries in AMPK research may offer some important insights into neurourology, suggesting a regulatory role of AMPK in detrusor contractility control, similar to its role in the heart [6].

The role of AMPK in the bladder, particularly regarding functional aspects such as contractility control, has not yet been investigated in detail [7], although some progress has been made in bladder cancer research $[8,9]$. In this issue of International Neurourology Journal, Kim [9] summarizes recent findings on the relationship between AMPK and bladder cancer that will provide basic information necessary for the development of research in contractility change in bladder function.

- Conflict of Interest: No potential conflict of interest relevant to this article is reported.

\section{REFERENCES}

1. Yoshimura N, Chancellor MB. Physiology and pharmacology of the bladder and urethra. In: Wein AJ, Kavoussi LR, Novick AC, Partin AW, Peters CA, editors. Campbell-Walsh urology. 10th ed. Philadelphia: Saunders; 2012. p. 1790-1.

2. Hardie DG. AMP-activated protein kinase: an energy sensor that regulates all aspects of cell function. Genes Dev 2011;25:1895-908.

3. Moore F, Weekes J, Hardie DG. Evidence that AMP triggers phosphorylation as well as direct allosteric activation of rat liver AMP- 
activated protein kinase: a sensitive mechanism to protect the cell against ATP depletion. Eur J Biochem 1991;199:691-7.

4. Carling D. AMP-activated protein kinase: balancing the scales. Biochimie 2005;87:87-91.

5. Papanas N, Maltezos E, Mikhailidis DP. Metformin and cancer: licence to heal? Expert Opin Investig Drugs 2010;19:913-7.

6. Oliveira SM, Zhang YH, Solis RS, Isackson H, Bellahcene M, Yavari A, et al. AMP-activated protein kinase phosphorylates cardiac troponin I and alters contractility of murine ventricular myocytes. Circ Res 2012;110:1192-201.

7. Choi BH, Jin LH, Kim KH, Kang SA, Kang JH, Yoon SM, et al.
Cystometric parameters and the activity of signaling proteins in association with the compensation or decompensation of bladder function in an animal experimental model of partial bladder outlet obstruction. Int J Mol Med 2013;32:1435-41.

8. Zheng QY, Jin FS, Yao C, Zhang T, Zhang GH, Ai X. Ursolic acidinduced AMP-activated protein kinase (AMPK) activation contributes to growth inhibition and apoptosis in human bladder cancer T24 cells. Biochem Biophys Res Commun 2012;419:741-7.

9. Kim WJ. Is 5'-AMP-activated protein kinase both Jekyll and Hyde in bladder cancer? Int Neurourol J 2015;19:55-66. 